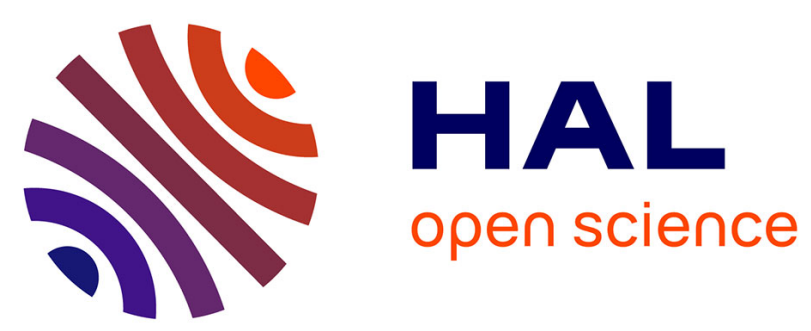

\title{
3D Scanning and Sensing Technique for the Detection and Remote Reading of a Passive Temperature Sensor
}

\author{
Dominique Henry, Patrick Pons, Hervé Aubert
}

\section{To cite this version:}

Dominique Henry, Patrick Pons, Hervé Aubert. 3D Scanning and Sensing Technique for the Detection and Remote Reading of a Passive Temperature Sensor. International Microwave Symposium (IMS), May 2016, San Fransisco, United States. hal-01396836

\section{HAL Id: hal-01396836 https://hal.science/hal-01396836}

Submitted on 16 Nov 2016

HAL is a multi-disciplinary open access archive for the deposit and dissemination of scientific research documents, whether they are published or not. The documents may come from teaching and research institutions in France or abroad, or from public or private research centers.
L'archive ouverte pluridisciplinaire HAL, est destinée au dépôt et à la diffusion de documents scientifiques de niveau recherche, publiés ou non, émanant des établissements d'enseignement et de recherche français ou étrangers, des laboratoires publics ou privés. 


\title{
3D Scanning and Sensing Technique for the Detection and Remote Reading of a Passive Temperature Sensor
}

\author{
D Henry, P Pons, H Aubert \\ LAAS-CNRS, Université de Toulouse, CNRS, INP, Toulouse, France
}

\begin{abstract}
This paper presents a novel technique for the detection and remote reading of passive temperature sensors. This technique is based on a 3D beam scanning performed by a FMCW radar for measuring the echo level of sensors distributed in a scene. The carrier frequency is $24 \mathrm{GHz}$ and two frequency modulation bandwidths are investigated (2 GHz and ISM 250 MHz). The fluctuation of the measured echo level is analyzed by using appropriate estimators and the derived temperature variation is displayed by using a convenient three dimensional representation of isosurfaces.

Index Terms - isosurfaces, passive sensors, radar imaging, radar remote sensing.
\end{abstract}

\section{INTRODUCTION}

Remotely reading passive sensors (tags without battery and integrated circuit) is an issue that has been investigated with different technologies and measurement techniques. A commonly used technology is surface acoustic waves (SAW) tags. It is nowadays perfectly handled to perform accurate tag identifications [1] and physical quantity measurement such as temperature [2] with an accuracy of $\pm 0.1^{\circ} \mathrm{C}$. A distance of interrogation of $20 \mathrm{~m}$ has been achieved [3]. However the operating frequencies do not exceed a few $\mathrm{GHz}$ and consequently the miniaturization of such tags is challenging. Radio Frequency Identification (RFID) tags are also popular for identification and sensing such as measuring temperature in harsh environments [4]. Intermodulation (or harmonic radars) can also remotely read tags with long achievable ranges such as the interrogation of acceleration sensors [5]. Nonetheless the gap between the received and transmitted operating frequencies can be problematic when taking into account radio regulations.

In this paper, a solution for detecting and remotely reading passive temperature sensors is proposed by using a novel measurement approach based on the use of a FrequencyModulated Continuous-Wave (FMCW) radar operating at 24GHz. This radar system, often applied for short-range detection, is commonly used to perform accurate ranging and imaging due to its large bandwidth capability [6]. The technique described here is based on a beam scanning of a scene to detect the tag and read the sensor information by using a chirp-z transformation and a convenient 3D visualization of the measured echo level. This technique applies for the first time imaging technique to the wireless reading of passive sensor tags. It has been recently reported by the authors to detect several passive tags with no sensing device [7][8]. In this communication the remote sensing of a passive temperature sensor is reported using two frequency bands and a new 3D display with isosurfaces for representing the measured temperature fluctuation.

This paper is composed of three parts. Section II explains the proposed radar measurement technique and section III starts with a brief description of the temperature sensor and focuses on the link between the return loss of the sensing device and the measured echo level due to the passive sensor. Sensor measurement results are discussed in section IV where the temperature is wirelessly derived from the analyze of the $3 \mathrm{D}$ echo level representation of the tag response.

\section{RADAR MEASUREMENT TECHNIQUE}

A FMCW radar is used to perform the passive tag interrogation. It generates a chirp with a modulation bandwidth $\mathrm{B}$ of $2 \mathrm{GHz}$ or $250 \mathrm{MHz}$. The frequency is modulated with a triangular waveform with duration of $1 \mathrm{~ms}$ for up and down ramps. The choice of the bandwidth is critical because it directly determines the depth resolution $d$ of the radar. A commonly used formula for the depth resolution is $\mathrm{d}$ $=\mathrm{c} / 2 \mathrm{~B}$ where $\mathrm{c}$ is the celerity of light. A depth resolution of $7.5 \mathrm{~cm}(\mathrm{~B}=2 \mathrm{GHz})$ or $60 \mathrm{~cm}(\mathrm{~B}=250 \mathrm{MHz})$ is expected. This resolution is the smallest separation distance between two distinguishable electromagnetic scatterers in the interrogation direction. We proceed to a 3D mechanical beam scanning with the help of a pan-tilt system automatically controlled by a computer. Moreover two different types of antennas are used for the transmitting and receiving the radar signals. A parabolic antenna of gain $33.5 \mathrm{dBi}$ is used for transmitting the chirp signal. It allows a beamwidth of $2^{\circ}$ in azimuth and elevation. The receiving antenna is a $5 \times 1$ patches array with a gain of $8.6 \mathrm{dBi}$. The beamwidth of this array is of $80^{\circ}$ in azimuth and $20^{\circ}$ in elevation. Taking into account the gain of the parabolic antenna and the input power at the radar frontend $(10.8 \mathrm{dBm})$ the EIRP (Equivalent Isotropically Radiated Power) is of $44.3 \mathrm{dBm}$. Here only the $\mathrm{E}$ (vertical) polarization is considered. A picture of the scanning system is shown in Fig 1.

A coaxial cable (length of $30 \mathrm{~cm}$ ) is used to connect the parabolic antenna feed horn to the radar transmission channel. To evaluate the distance between a target and the radar front- 
end, the effective length of the cable and the distance between the parabolic reflector and its feeding horn antenna have to be taken into account. The beat frequency spectrum is derived from a chirp-z transformation [9]. The echo level associated to a resolution cell is calculated by taking into account the gain and radiation pattern of the transmitting and receiving radar antennas.

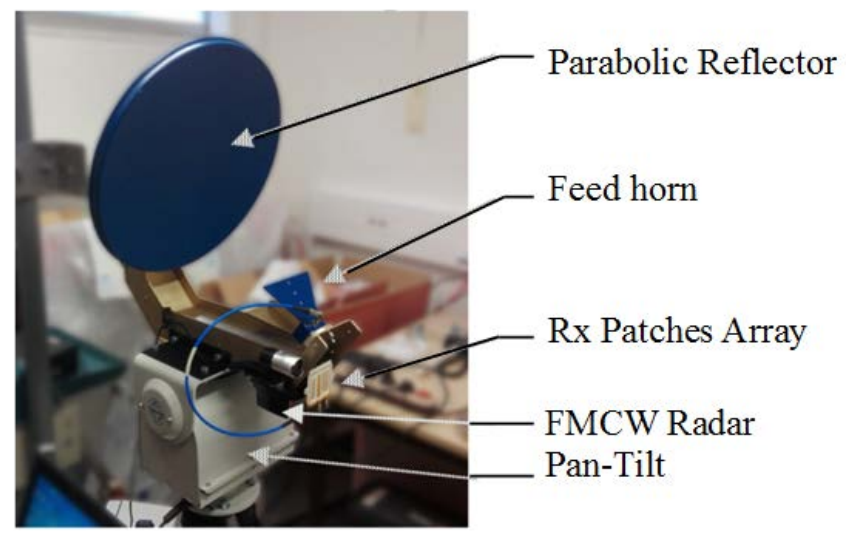

Fig. 1. 3D beam scanning system. The radar transmitting antenna is a parabolic antenna and the receiving antenna is an array of patches .

\section{ECHO LEVEL MEASUREMENT FOR A VARIABLE LOADING IMPEDANCE}

\section{A. Sensor characteristics}

The system described in the previous section is used here to measure the variation of the echo level generated by a sensor. The sensor is designed for spatially separating the structural and the sensing modes [10]. It is composed of three main elements:

(1) the antenna: its shape defines the structural scattering mode. The sensor antenna is here a horn antenna with a gain of $20 \mathrm{dBi}$, a beamwidth of $60^{\circ}$ and an input impedance of $50 \Omega$;

(2) the sensing device: it is a passive component requiring no power supply (battery-less) and no integrated circuit (chipless). In this section a variable attenuator is first used to simulate the input impedance variation of sensing device impedance. In Section IV a thermistor will be used;

(3) A length of transmission line: it is here a coaxial cable which allows separating the echoes from the structural and sensing modes.

\section{B. Echo level measurement}

Measurement results using the variable attenuator as a tag loading impedance are displayed on Fig 2. The tag is located at $2.4 \mathrm{~m}$ from the radar and interrogated. Due to the lower depth resolution when $\mathrm{B}=250 \mathrm{MHz}$ (ISM band), structural and sensing modes can be identified for $\mathrm{B}=2 \mathrm{GHz}$ only. As expected the structural mode is located at $2.4 \mathrm{~m}$ and the sensing mode is placed $1.35 \mathrm{~m}$ further. In order to analyze the echo level fluctuation as the loading impedance varies, we define two estimators called $\mathrm{P}_{\mathrm{Max}}$ and $\mathrm{dP}_{\mathrm{Max}}$ : $\mathrm{P}_{\mathrm{Max}}$ is the maximal echo level and $\mathrm{dP}_{\mathrm{Max}}$ is the local normalized variation

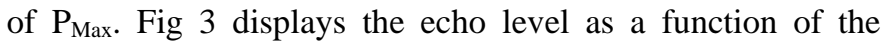
return loss at the loading impedance input. A linear variation is obtained within a $4.5 \mathrm{~dB}$ full-scale measurement range when $\mathrm{B}=2 \mathrm{GHz}$. When $\mathrm{B}=250 \mathrm{MHz}$ (ISM band) this range is of $3 \mathrm{~dB}$ for a return loss between $-18 \mathrm{~dB}$ to $-13 \mathrm{~dB}$.
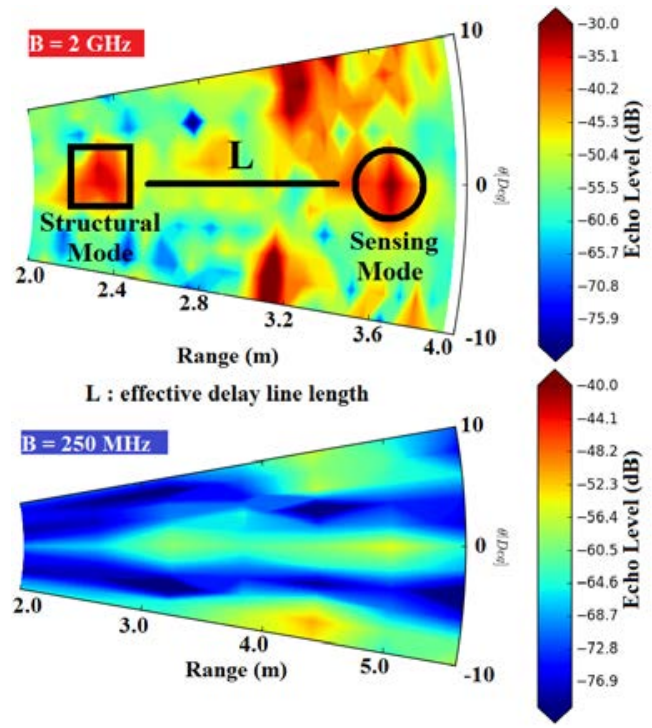

Fig. 2. 2D representation in a given elevation cut plane $\left(\varphi=0^{\circ}\right)$ of the echo level when the sensing device is replaced by an impedance of $77 \Omega$ and for $2 \mathrm{GHz}$ (top) and $250 \mathrm{MHz}$ (bottom) bandwidth modulations
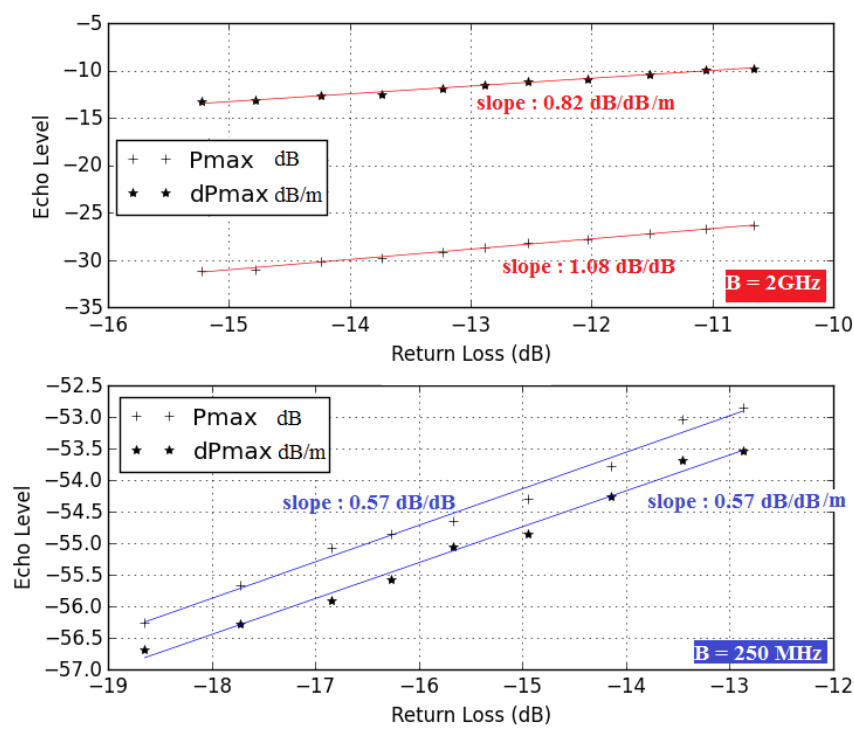

Fig. 3. Echo level variation as a function of the return loss at the variable attenuator input for two estimators ( $\mathrm{P}_{\mathrm{Max}}$ and $\left.\mathrm{dP}_{\mathrm{Max}}\right)$ with $2 \mathrm{GHz}$ (top) and 250MHz (bottom) bandwidth modulations

\section{Application to Temperature SENSOR INTERROGATION}

The variable attenuator used in the Section III is now replaced by a thermistor. The resulting passive temperature 
sensor is located at 2.4 meters from the radar. The temperature derived from the $\mathrm{P}_{\text {Max }}$ and $\mathrm{dP}_{\text {Max }}$ estimators is shown in Table $\mathrm{I}$. When $\mathrm{B}=2 \mathrm{GHz}$ a full-scale measurement range of $5 \mathrm{~dB}$ is obtained for a temperature variation $\Delta \mathrm{T}=$ $30^{\circ} \mathrm{C}$ and the measurement sensitivity is found to be 0.16 $\mathrm{dB} /{ }^{\circ} \mathrm{C}$. The temperature variation is still detectable in the ISM band $(B=250 \mathrm{MHz})$ but the measurement sensitivity is lower $\left(0.09 \mathrm{~dB} /{ }^{\circ} \mathrm{C}\right)$. Consequently the use of the larger bandwidth $\mathrm{B}$ allows achieving higher measurement sensitivity.

The isosurface representation of the temperature variation is shown in Fig 4. It displays several layers of equal level values that are interpolated inside a specific volume. In this convenient representation, the set of resolution cells for which the echo level is higher than a given threshold is a 3D structure of volume $\mathrm{V}$. When the temperature increases the volume $\mathrm{V}$ increases accordingly. This volume depends also on the modulation bandwidth $B$ and on the choice of an appropriate threshold. The volume $\mathrm{V}$ is given in Table I for the two bandwidths and at various temperatures. The three estimators $\mathrm{P}_{\mathrm{Max}}, \mathrm{dP}_{\mathrm{Max}}$ and $\mathrm{V}$ are given with a threshold of $40 \mathrm{~dB}$ for $\mathrm{B}=2 \mathrm{GHz}$ and $-70 \mathrm{~dB}$ for $\mathrm{B}=250 \mathrm{MHz}$. It can be observed that these estimators change gradually as the temperature varies and consequently, they can be used for the remote derivation of the temperature variation.

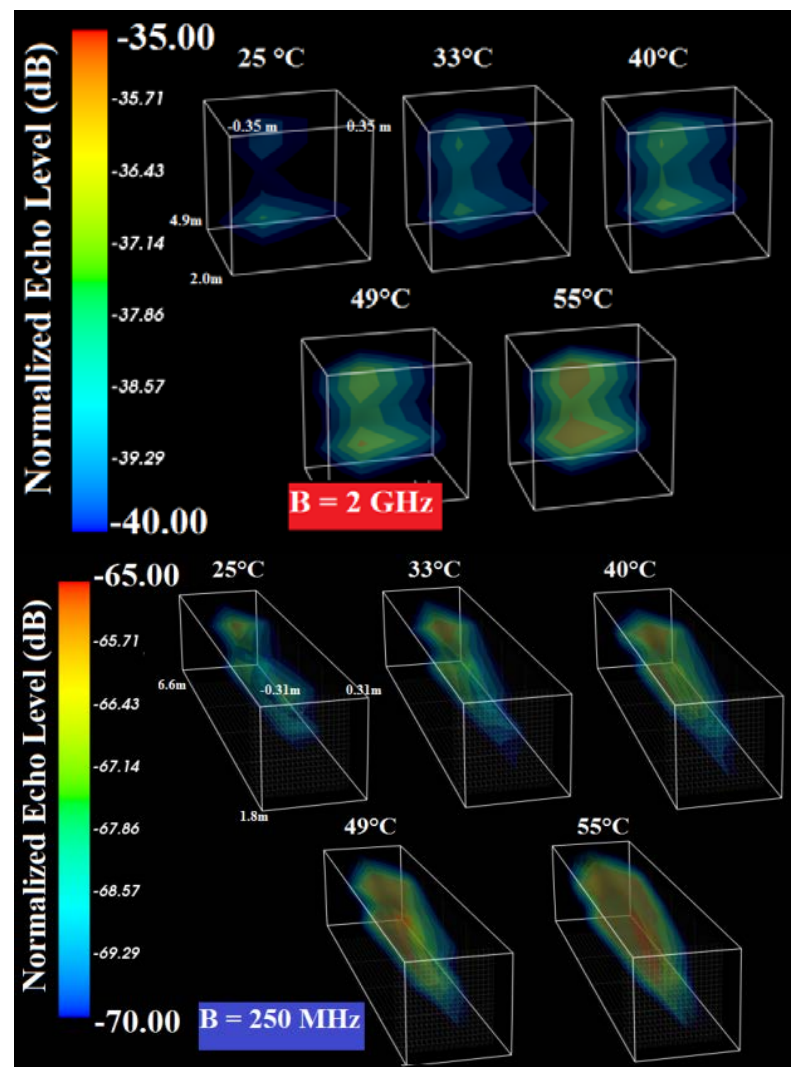

Fig. 4. 3D representation with isosurfaces of the normalized echo level due to the sensing mode at different temperatures with $2 \mathrm{GHz}$ (top) and 250MHz (bottom) bandwidth modulations

\section{CONCLUSION}

The remote measurement of temperature is performed here from the interrogation of passive temperature sensors by a 3D beam scanning FMCW radar. The temperature variation is

TABLE I

TEMPERATURE SENSOR CHARACTERISTICS

\begin{tabular}{|c|c|c|c|c|c|c|}
\hline & \multicolumn{5}{|c|}{ Estimators } \\
$\mathbf{T}\left({ }^{\circ} \mathrm{C}\right)$ & \multicolumn{3}{|c|}{$\mathrm{B}=2 \mathrm{GHz}$} & \multicolumn{3}{c|}{$\mathrm{B}=250 \mathrm{MHz}$} \\
& $\mathrm{P}_{\mathrm{Max}}$ & $\mathrm{dP}$ Max & $\mathrm{V}$ & $\mathrm{P}_{\mathrm{Max}}$ & $\mathrm{dP} \operatorname{Max}$ & $\mathrm{V}$ \\
& $(\mathrm{dB})$ & $(\mathrm{dB} / \mathrm{m})$ & $\left(\mathrm{cm}^{3}\right)$ & $(\mathrm{dB})$ & $(\mathrm{dB} / \mathrm{m})$ & $\left(\mathrm{cm}^{3}\right)$ \\
\hline 25 & -33.1 & -13.3 & $1,4 \mathrm{E} 2$ & -57.7 & -54.7 & $82 \mathrm{E} 3$ \\
\hline 33 & -32.3 & -12.4 & $2.2 \mathrm{E} 2$ & -57.2 & -53.9 & $98 \mathrm{E} 3$ \\
\hline 40 & -31.0 & -11.5 & $3.2 \mathrm{E} 2$ & -56.9 & -53.5 & $125 \mathrm{E} 3$ \\
\hline 49 & -30.2 & -10.8 & $3.7 \mathrm{E} 2$ & -56.2 & -53.0 & $149 \mathrm{E} 3$ \\
\hline 55 & -28.7 & -9.6 & $5.4 \mathrm{E} 2$ & -55.1 & -52.1 & $191 \mathrm{E} 3$ \\
\hline
\end{tabular}

detectable using isosurfaces with a measurement sensitivity of $0.16 \mathrm{~dB} /{ }^{\circ} \mathrm{C}$ at 2.4 meters. Other physical or chemical quantities (e.g., pressure, strain or gas concentration) could be remotely derived by using the proposed wireless technique and preliminary experimental results (not reported here) show that interrogation distance up to 10 meters can be achieved

\section{REFERENCES}

[1] Klaffenbock, M.; Schuster, S.; Scheiblhofer, S.; Stelzer, A., "Model-Based Identification Method for Pulse Position Coded Surface Acoustic Wave Identification Tags," in IEEE Transactions on Instrumentation and Measurement, vol.63, no.10, pp.2405-2413, Oct. 2014

[2] Schuster, S.; Scheiblhofer, S.; Reindl, L.; Stelzer, A., "Performance evaluation of algorithms for SAW-based temperature measurement," in IEEE Transactions on Ultrasonics, Ferroelectrics, and Frequency Control, vol.53, no.6, pp.1177-1185, June 2006

[3] Ping Li; Hua Xie; Wen, Yumei; Chuan Wang; Shiyuan Huang; Zhiwei Ren; Junjie He; Dang Lu, "A SAW passive wireless sensor system for monitoring temperature of an electric cord connector at long distance," in 2011 IEEE Sensors, pp.18311834, 28-31 Oct. 2011

[4] Karim, H.; Delfin, D.; Shuvo, M.A.I.; Chavez, L.A.; Garcia, C.R.; Barton, J.H.; Gaytan, S.M.; Cadena, M.A.; Rumpf, R.C.; Wicker, R.B.; Yirong Lin; Choudhuri, A., "Concept and Model of a Metamaterial-Based Passive Wireless Temperature Sensor for Harsh Environment Applications," in IEEE Sensors Journal, vol.15, no.3, pp.1445-1452, March 2015

[5] Jinsong Song; Pesonen, N.; Viikari, V., "Long range passive wireless MEMS-based inclination or acceleration sensor utilizing the intermodulation communication principle," in 2014 IEEE International Wireless Symposium (IWS), pp.1-4, 24-26 March 2014

[6] Jaeschke, T.; Bredendiek, C.; Pohl, N., "3D FMCW SAR Imaging based on a $240 \mathrm{GHz}$ SiGe Transceiver Chip with Integrated Antennas," in 2014 German Microwave Conference (GeMIC), pp.1-4, 10-12 March 2014

[7] This reference has been removed because it establishes a direct connection to the authors' names

[8] This reference has been removed because it establishes a direct connection to the authors' names 
[9] Rabiner, L.; Schafer, R.W.; Rader, C.M., "The chirp z-transform algorithm," in IEEE Transactions on Audio and Electroacoustics, vol.17, no.2, pp.86-92, Jun 1969

[10] Harrington, Roger F., "Theory of loaded scatterers," Proceedings of the Institution of Electrical Engineers, vol.111, no.4, pp.617623, April 1964 